\title{
Lessons Learned from Changing Content Delivery Methods in Engineering Statics
}

\section{Dr. Laura Doyle, Santa Clara University}

Dr. Laura Doyle is a lecturer in the Civil Engineering Department at Santa Clara University where she teaches undergraduate courses in civil engineering. Before coming to SCU, Laura was a post doctoral scholar for the John Muir Institute of the Environment at University of California, Davis where she used multi-dimensional models to examine water quality of the San Francisco Bay Delta system. She earned her masters and doctoral degrees at UC Davis and her undergraduate degree (all in civil engineering) is from Loyola Marymount University.

\section{Dr. Tonya Lynn Nilsson P.E., Santa Clara University}

Tonya Nilsson is a Lecturer in Civil Engineering at Santa Clara University (SCU), where she is also one of six Faculty Associates in their Collaborative for Teaching Innovation. Prior to joining SCU, Tonya was an Associate Professor at CSU - Chico. 


\title{
Lessons Learned from Changing Content Delivery Methods in Engineering Statics
}

\begin{abstract}
This work examines the impact different pedagogical approaches in an engineering statics course had on student learning, long-term retention of material, student interest in their field of study and how the impact differs with gender. During the 2015-2016 academic year, five sections of engineering statics were taught, for a total of approximately 130 students including all sophomore civil and mechanical engineering students along with junior and senior electrical engineering students and some bio-engineering students pursuing a minor in mechanical engineering. Four sections, each taught by different professors, implemented significant pedagogical changes. Course changes incorporated flipped classes, flipped-flipped classes and many hands on activities. One of the professors taught the fifth section as a control group using their normal teaching style that includes more traditional active learning methods like group work, questioning and demonstrations
\end{abstract}

To assess the impact of the pedagogical approaches, the statics concept inventory developed by Paul Steif was used twice during the course to assess pre- then post- course knowledge. The concept inventory was also used to assess long-term retention of a cohort of students one to four months after they finished the course. Results between the control class and the students taught with the inverted model are compared. Students filled out a post-course survey asking for input on activities and videos and how they perceived the course helped them learn and engage in the subject and engineering.

Results from this work indicate the specific active learning technique implemented is less important in student learning gains and student engagement than the experience and training of the faculty member in effectively implementing active learning methodologies. Students in all sections showed long-term retention of course topics and had similar preferences in contentdelivery methods. Gender differences were striking, with female students gaining significantly to their male counterparts. The results of this study provide insight for other researchers hoping to implement active learning approaches in introductory engineering courses.

\section{Introduction}

Engineering statics is one of the first classes specific to the fields of civil and mechanical engineering and an important opportunity to engage engineering students in a challenging subject in their field of study. Extensive lecturing is still the most common form of instruction for engineering faculty at Santa Clara University, with over 70\% of STEM faculty self-reporting lecturing "most" or "all" of the time. ${ }^{1}$ A recent meta-analysis by Freeman, et.al. ${ }^{2}$ of over 225 studies in STEM education, indicates that students in STEM courses taught with extensive lecturing are 1.5 times more likely to fail, earn a D, or withdraw from the course than students taught with active-learning methods in the same STEM course subject. To facilitate other SCU faculty in adopting more active approaches in the statics course, the authors developed activelearning modules for specific statics course content with the intent to document the modules' effectiveness in improving student performance, material retention and engagement. This work was supported by an internal grant. During the course of this work, two additional faculty agreed to pilot the modified lessons in their sections and helped develop lesson activities. 
As a condition of the grant, a minimum of ten learning modules based on the flipped instructional model were created for this core engineering course, which included developing the out-of-class videos, hands-on activities and physical models to support in-class activities.

Flipping the statics classroom has seen success at other institutions, including Carnegie-Mellon University and the University of Puerto Rico Mayaguez. ${ }^{3,4}$ Additional studies show that even if the student performance did not improve after an inverted engineering class model, student engagement in the material did increase: an important consideration at the start of the engineering education career. $5,6,7$

Five of the "flipped" learning modules extended this approach by using the flipped-flipped classroom model. In this variation on the inverted classroom, students initially experience a concept by completing an in-class, hands-on activity that demonstrates a theory's behavior without any theoretical explanation. This is followed by the typical flipped approach with homework to view a video explaining the theory and solve related problems and additional inclass, problem solving in the next class meeting. Early research indicates the flipped-flipped methodology improves learning, retention and engagement. ${ }^{8}$

Finally, three hands-on activities were developed to allow students to experientially learn about pulleys, three dimensional support reactions and how loads distribute to supports on a beam. These activities were not used in the control classroom.

The intent of this work was to provide insight on the following questions to guide faculty on instructional approaches that had the greatest impact on student learning and retention:

1. Does inverting the statics classroom help to improve student self-reported participation?

2. How do flipped-flipped approaches compare to the standard flipped model in terms of student perception of teaching effectiveness and their reported engagement?

3. Is a demo enough? Should students do a hands-on activity for deeper learning and engagement?

4. Does inverting the statics classroom increase material knowledge gain?

Freeman, et al. showed that straight lecturing is not a best practice in STEM education and recommends any new pedagogical approach be assessed against a proven active approach and not traditional, extensive lecturing. ${ }^{2}$ As such, the control class will use more conventional activelearning methods such as group work, demonstrations and student questioning techniques to determine if flipping and hands-on activities provide greater learning gains.

\section{Methods}

In the fall of 2015, four sections of statics were taught to primarily civil and mechanical engineering sophomore students, with one additional section taught during the following winter 2016 quarter. A total of 4 professors taught the 5 sections as summarized in Table 1.

Professor 1's existing active-learning curriculum was used as the base curriculum for all five sections. This curriculum uses interactive lecturing based on the ExCEEd teaching model and includes group problem solving, physical models and student questioning techniques. ${ }^{9}$ Twelve of 
the thirty 65-minute class lessons were modified from the existing curriculum to included flipped, flipped-flipped or hands-on physical activities. Fourteen lessons remained the same and the remainder of the lessons were review or exams. Sections A, B, D and E included the twelve modified lessons as summarized in Table 2 while section $\mathrm{C}$ used the existing curriculum.

Table 1. Identification of term when taught and instructor of each section considered in this work. Note sections A and $\mathrm{C}$ were taught by the same professor.

\begin{tabular}{|l|l|l|l|}
\hline Section & Term Taught & Instructor & Course Day \& Time \\
\hline Section A & Fall 2015 & Professor 1 & MWF - 9:15-10:20 am \\
\hline Section B & Fall 2015 & Professor 2 & MWF - 10:30-11:35 am \\
\hline Section C & Fall 2015 & Professor 1 & MWF - 11:45 am $-12: 50 \mathrm{pm}$ \\
\hline Section D & Fall 2015 & Professor 3 & T/Th - 8:30-10:20 am \\
\hline Section E & Winter 2015 & Professor 4 & MWF - 10:30-11:35 am \\
\hline
\end{tabular}

Table 2. Summary of teaching methods used to teach course topics in the experimental sections.

\begin{tabular}{|c|c|c|c|c|}
\hline \multicolumn{5}{|c|}{ Topics covered the same in both sections (using Active Lecture techniques) } \\
\hline \multirow{2}{*}{ Introduction } & Couples & $\begin{array}{c}\text { Equivalent Force } \\
\text { Systems }\end{array}$ & 3D moments & Centroid \\
\hline 3D Equilibrium & Trusses & Frames & Ethics & Friction \\
\hline \multirow{7}{*}{ Topics that used flipped lessons for sections A,B,D \& E } & Machines \\
\hline Vector Review & 3D Vectors & $\begin{array}{c}\text { Parallel-Axis } \\
\text { Theorem }\end{array}$ & $\begin{array}{c}\text { 2D Support } \\
\text { Reactions }\end{array}$ & Topics that used flipped-flipped lessons for sections A, B, D \& E \\
\hline Moments & $\begin{array}{c}\text { Understanding } \\
\text { Internal Shear and } \\
\text { Moments }\end{array}$ & $\begin{array}{c}\text { Writing Equations } \\
\text { of Shear and } \\
\text { Moment }\end{array}$ & $\begin{array}{c}\text { Graphical Methods - } \\
\text { Shear and Moment } \\
\text { Diagrams }\end{array}$ & Moment of Area \\
\hline \multicolumn{7}{|c|}{ Topics that used demos \& hands-on activities only in sections A, B, D \& E } \\
\hline
\end{tabular}

Professor 1 taught sections A and C. Professors 2 and 3, who taught sections B and D respectively, historically use class demonstrations but teach with a lecturing style that is not highly interactive. Professor 4, who taught Section E, regularly uses interactive methods.

The professors met each week during the fall 2015 quarter to finalize the lessons for the following week. The development of the course activities was a collaboration, with the authors taking a lead role but each professor taking ownership of at least one lesson. In the fall quarter, all sections were assigned the same homework assignments, but midterm and final exams differed to ensure academic integrity.

To change the curriculum, the team of professors first identified in-class activities and demonstrations that could be used to complement lessons. For activities that could take the entire 65 minute class period, the class was flipped to allow time for the activity. This resulted in five flipped lessons. For these flipped classes, students watched 15-minute video lectures and completed homework problems supported by the video content before coming to class. Five course topics were introduced using the flipped-flipped model where students' introduction to a concept was through a hands-on activity or physical demo with no theory. The lesson's 
homework followed the activity with a short video explaining the theory and assigned homework problems. Additional problem solving and activities to support the video occurred in the following lesson; a method in-line with the normal flipped model.

An example of the flipped-flipped curriculum was an activity called "Non-concurrent forces". The activity required students to balance a 12 inch ruler on a wooden half-round and balance washers on either side of the dowel as seen in Figure 1. Students were required to balance the ruler with washers for: equal distance and equal mass, and unequal distance and unequal mass and recorded the mass and distances. Using the recorded values, students were asked to develop the mathematical relationship that represents the balanced ruler. A majority of the students were able to develop the relationship $\mathrm{F}_{1} \mathrm{~d}_{1}=\mathrm{F}_{2} \mathrm{~d}_{2}$. The concept of a moment was never mentioned.

The homework following the lesson required students watch a video on moment theory, as shown in Figure 2 that was created in Doceri and uploaded to YouTube. Two homework problems requiring the calculation of moments in two and three dimensions

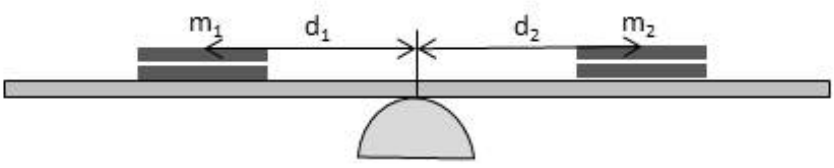

Figure 1. Set up for non-concurrent forces activity which introduces students to the concept of moments. were due at the next class meeting to prepare students for in-class activities where they worked individually and in groups to solve additional moment problems.

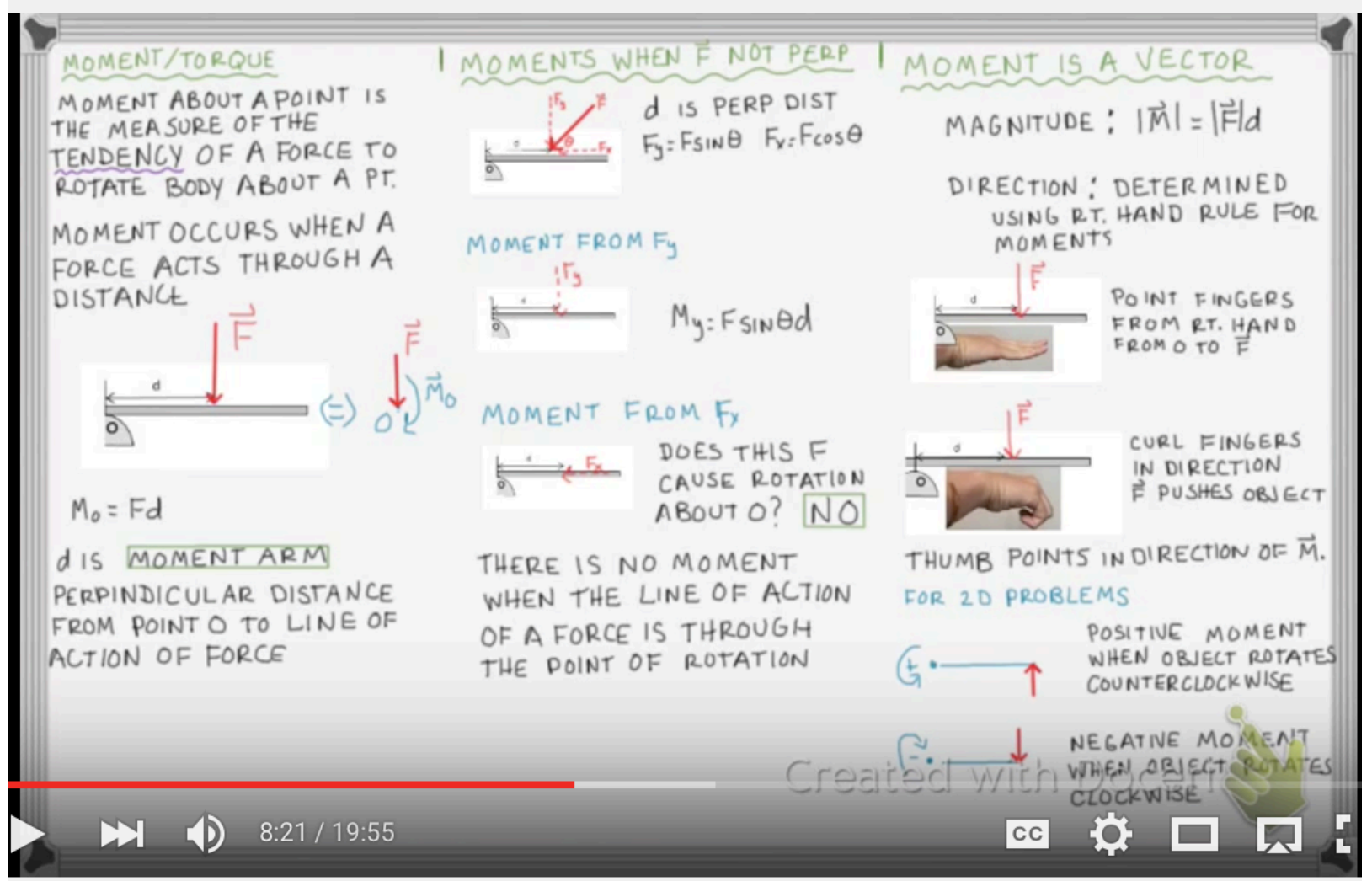

Figure 2. Screenshot of video used for introduction to 2D moments. 
A variety of methods to assess the effectiveness of these changes were used. First, a statics concept inventory developed by Paul Steif was used twice during the course to asses pre- and post- course knowledge. ${ }^{10}$ The concept inventory was also used to assess long-term retention of a cohort of students one to four months after they finished the course. Exam performance for students in sections $\mathrm{A}$ and $\mathrm{C}$ were compared using exam problems of similar difficulty for the same topic. Student performance was compared based on their class section and with the student's pre-requisite course grade. Student self-reported engagement in course topics and overall interest in engineering was determined through student surveys at the end of the course.

The concept inventory specifically addresses the following areas:

- FBD - Identifying forces acting on a subset of a system of bodies

- Newton's $3^{\text {rd }}$ Law - forces between two contacting bodies must be equal and opposite.

- Static Equivalence - static equivalence between forces, couples and combinations.

- Roller - direction of force between pin and slot of a member

- Negligible Friction - direction of force between frictionless bodies in point of contact.

- Representation - Representing unknown loads at various connections

- Friction-Coulomb's law and friction forces

- Equilibrium - consideration of both force and moment balance in equilibrium

- Slot - direction of force between pin and slot of a member

\section{Section Demographics}

During the fall and winter quarters of the 2015 - 2016 school year, 130 students enrolled in statics, with 115 of those students enrolled in the fall quarter. Table 3 summarizes the enrollment in each section removing the fifteen total students who did not give permission to have their results included in this work. Table 3 also provides the number of male and female students and the average incoming grade from the prerequisite physics course on a four point scale with AP credit assigned 3.5 points. When AP credit is not considered, section $\mathrm{C}$ had the highest incoming average grade.

Table 3. Summary of student demographics by section. Total students are students granting permission on both pre- and post- survey to use their results. Average incoming grade assigns numeric value to the grade for the physics pre-requisite. Some students have AP credit (CR) for this course, AP credit was assigned a numeric value of 3.5.

\begin{tabular}{|c|c|c|c|c|c|c|c|c|c|}
\hline Section & $\begin{array}{c}\text { Total } \\
\text { Students }\end{array}$ & $\begin{array}{c}\text { Count } \\
\text { Females }\end{array}$ & $\begin{array}{c}\text { Count } \\
\text { Male }\end{array}$ & $\begin{array}{c}\text { Average } \\
\text { Incoming } \\
\text { Grade } \\
\text { (with CR) }\end{array}$ & $\begin{array}{c}\text { Average } \\
\text { Incoming } \\
\text { Grade (without } \\
\text { CR) }\end{array}$ & \multicolumn{2}{|c|}{$\begin{array}{c}\text { Average Prereq } \\
\text { Grade (with CR) } \\
\text { Female|Male }\end{array}$} & $\begin{array}{c}\text { Average Prereq } \\
\text { Grade (without } \\
\text { CR) } \\
\text { Female|Male }\end{array}$ \\
\hline A & 28 & 12 & 15 & 3.02 & 2.94 & 2.65 & 3.12 & 2.28 & 3.07 \\
\hline B & 26 & 5 & 21 & 3.13 & 2.99 & 3.34 & 3.06 & 3.23 & 2.92 \\
\hline C & 23 & 4 & 19 & 3.13 & 3.06 & 2.64 & 3.16 & 2.43 & 3.10 \\
\hline D & 23 & 4 & 19 & 2.94 & 2.89 & 2.80 & 2.93 & 2.66 & 2.9 \\
\hline E & 15 & 3 & 12 & 2.82 & 2.55 & 2.17 & 3.00 & 1.50 & 2.81 \\
\hline
\end{tabular}

As seen in Table 3, average pre-requisite grade differed by gender. Section A had the highest percent of females with over $40 \%$ compared to approximately $20 \%$ females for the other 
sections. In sections $\mathrm{A}, \mathrm{C}, \mathrm{D}, \& \mathrm{E}$ the male students entered the class with a stronger performance in the prerequisite physics course

\section{$\underline{\text { Results - Student Performance }}$}

Concept Inventory

The Statics Concept Inventory was

administered at the start and end of the quarter to measure student gains. Results from the pre- and post- tests for sections A-E are shown in Table 4 and Figure 3 and 4. Due to the short ten week quarter, Coulomb's law and friction forces (a review from Physics) received only cursory attention and student performance on the concept inventory resultantly saw no change in the post- results. As such, these friction results were not included in any of the data.

Male students performed better than female

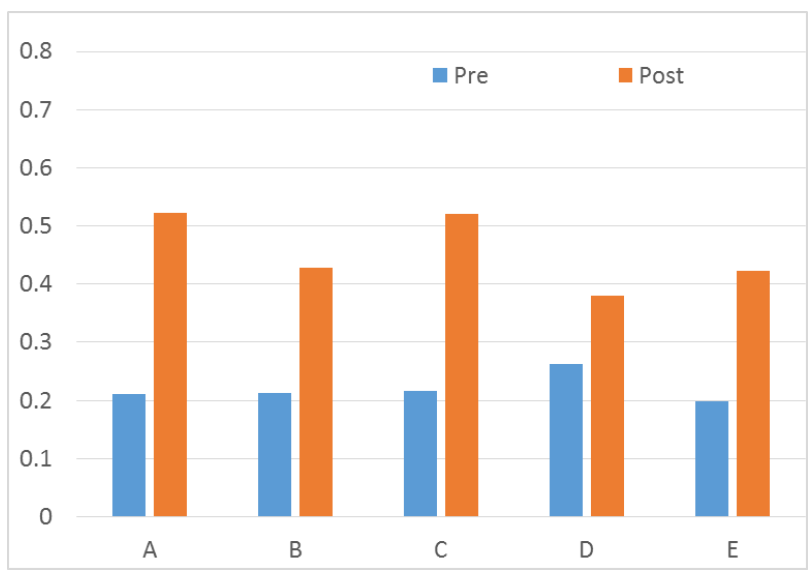

Figure 3. Average pre- and post-concept inventory results by section. Pre- and postresults do not include Coulomb's law and friction forces. students on the pre-test in all sections. This is in-line with the lower incoming female prerequisite course grades for all sections except section B where the female students had the highest average prerequisite grades but the lowest average performance on the concept inventory. Table 4 and Figure 3 show section A had the highest scores on the post-test for both male and female students and the highest total percent increase on concept inventory score as a class. Female students in section B saw the greatest gain on the post-test with average scores improved by $322 \%$. Section $\mathrm{C}$ shows the greatest gap between male and female scores on the post-concept inventory. However, the female students in this section increased their scores by $178 \%$ while the male students only saw a $126 \%$ increase.

Table 4. Pre- and Post-Concept Inventory scores for each section, separated by gender, where a 1.0 is a perfect score.

\begin{tabular}{|c|c|c|c|c|c|c|c|c|c|c|c|}
\hline \multirow[b]{2}{*}{ Section } & \multicolumn{4}{|c|}{ Pre-Concept Inventory Average } & \multicolumn{4}{|c|}{ Post-Concept Inventory Average } & \multicolumn{3}{|c|}{$\begin{array}{c}\text { Percent Increase on } \\
\text { Pre- versus } \\
\text { Post- Concept Inventory }\end{array}$} \\
\hline & Count & Female & Count & Male & Count & Female & Count & Male & Female & Male & $\begin{array}{l}\text { Total } \\
\text { Class }\end{array}$ \\
\hline $\mathbf{A}$ & 12 & 0.194 & 13 & 0.224 & 13 & 0.568 & 14 & 0.607 & $192 \%$ & $170 \%$ & $165 \% *$ \\
\hline B & 4 & 0.107 & 18 & 0.257 & 4 & 0.452 & 14 & 0.450 & $322 \%$ & $75.4 \%$ & $96.4 \%$ \\
\hline $\mathbf{C}$ & 4 & 0.143 & 19 & 0.253 & 2 & 0.397 & 17 & 0.571 & $178 \%$ & $126 \%$ & $134 \%$ \\
\hline $\mathbf{D}$ & 6 & 0.206 & 21 & 0.292 & 4 & 0.416 & 16 & 0.372 & $102 \%$ & $27.2 \%$ & $39.6 \%$ \\
\hline $\mathbf{E}$ & 2 & 0.167 & 11 & 0.205 & 2 & 0.438 & 6 & 0.471 & $163 \%$ & $108 \%$ & $112 \%$ \\
\hline
\end{tabular}

* One student in Section A completed the post-concept inventory and self-identified as gender non-conforming. Their individual results are not included in the female or male column. This student had a negative learning gain on the concept inventory resulting in a lower than expected total class average if only looking at male and female students. 
Figure 4 shows student performance on the concept inventory by topic and section. Section C has the highest post- score for four of the eight topics, while Sections A and E both have the highest post- score for two of the eight topics. Neither sections B or D have the highest postscore for any of the topics.

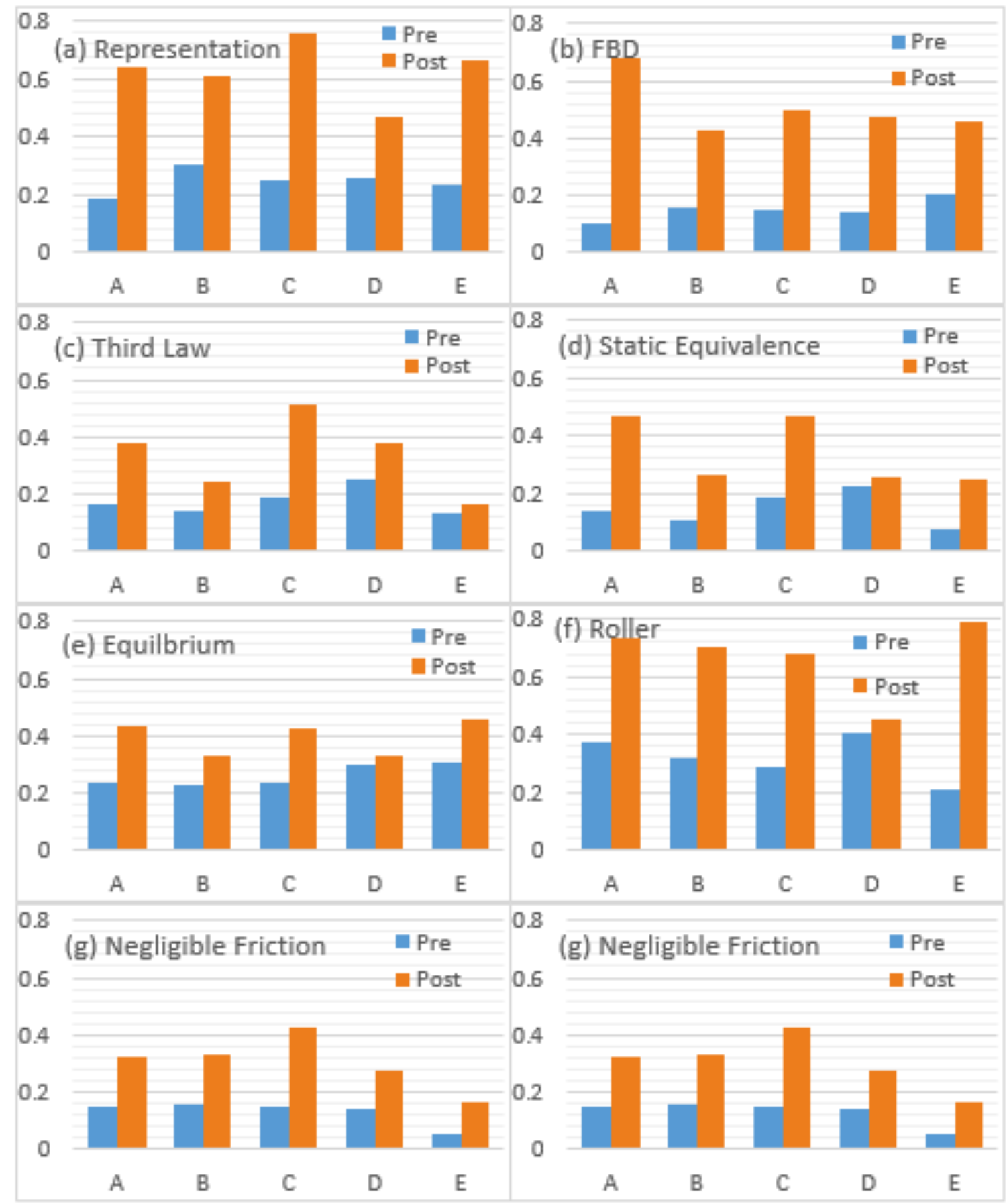

Figure 4. Pre- and post- concept inventory scores by topic for each Sections A, B, C, D and $\mathrm{E}$. 


\section{Concept Inventory Retention}

Seventeen civil engineering students retook the concept inventory as their first homework assignment in mechanics of materials four weeks after completing statics. An additional 50 mechanical engineering students completed the concept inventory as their first mechanics of materials assignment three and a half months after completing statics and gave permission for their results to be published. Figure 5 shows student long-term retention by section. Figure 5 only contains those civil and mechanical engineering students who continued in the mechanics sequence and took all three tests. The change in sample size between the post- and retention (112 students completed the pretest, 91 completed the pre- and posttest, and only 51 completed all three tests) altered the average post- concept inventory score as compared to Figure 3.

When including only the sample of students that took all three tests, section B out-performed the other sections on both the post- and retention concept inventories, which is not the case when all students are included. Interestingly, the average retention scores for these students where higher than the post- scores for all sections.

To determine if there was any significance to the variation between class sections, and specifically if there was an interaction between concept inventory scores (pre-, post-, and retention) and class sections, a two-way mixed ANOVA was run using the smaller sample size with all the concept inventory scores.

The two-way mixed ANOVA revealed that there is no statistically significant interaction

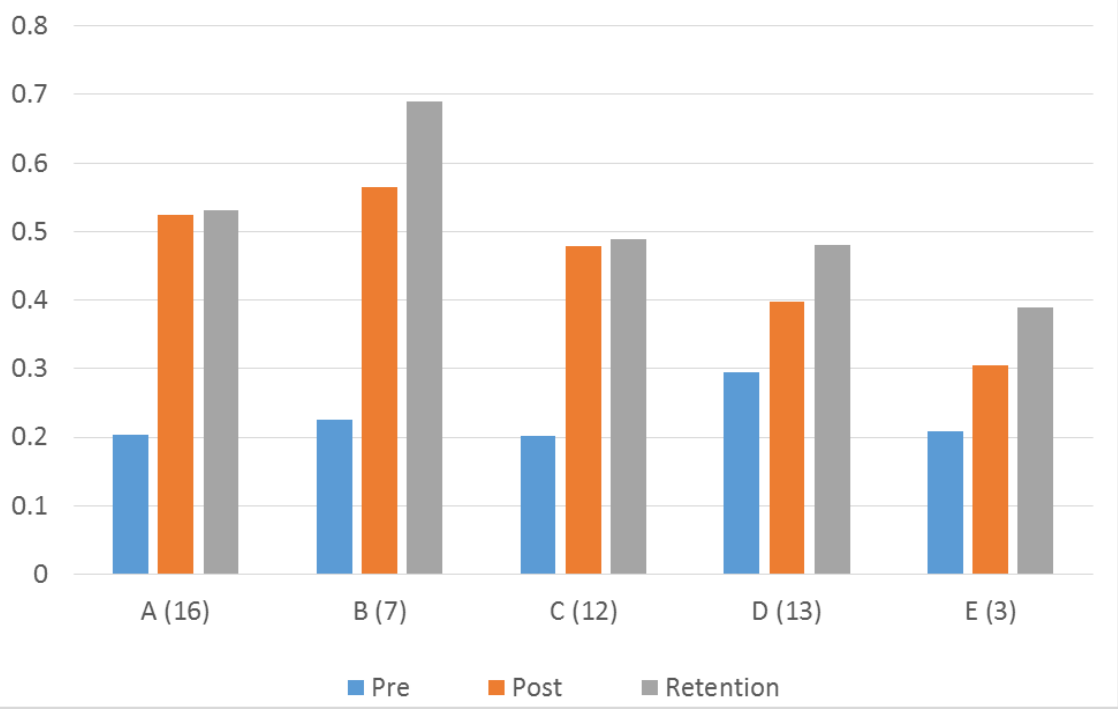

Figure 5. Students' pre, post- and retention concept inventory scores. These averages include only those students who took all three tests resulting in different averages from just the pre- or post- values. Numbers in parentheses indicate the number of students included in the averages. between class section and concept inventory scores (pre, post- and retention) in the smaller sample, $F(8,92)=1.90, p=.08$, partial $\eta^{2}=.14$. Similarly, the main effect of group (i.e., class section) showed there is not a statistically significant difference in concept inventory scores between classes $F(4,46)=1.24, p=.31$, partial $\eta^{2}=.10$. There is, however, a significant main effect for time, showing that students in all sections made gains in knowledge over time. The main effect of time showed a statistically significant difference in concept inventory scores at the different time points, $F(2,92)=37.35, p<.001$, partial $\eta^{2}=.45$.

A closer examination of the changes over time revealed that the post- concept inventory score was .24 points higher than the pretest score, a statistically significant difference, $p<.001$. Similarly, the retention score was .29 points higher than the pre-test score, also a statistically 
significant difference, $p<.001$. Finally the retention-test was .05 points higher than the post-test but this difference was not statistically significant, $p=.08$.

Because the first two-way mixed ANOVA revealed no statistically significant difference between the post-test and the retention test, in order to increase the sample size, the analysis was repeated for only the pre- and post- tests. This increased the sample size to 91 students who took both the pre- and post- test. A comparison of pre- and post- test average scores for these 91 students is shown in Figure 6. Figure 6 varies slightly from Figure 3 as Figure 3 contains all students who took the posttest even if they missed the pre-test.

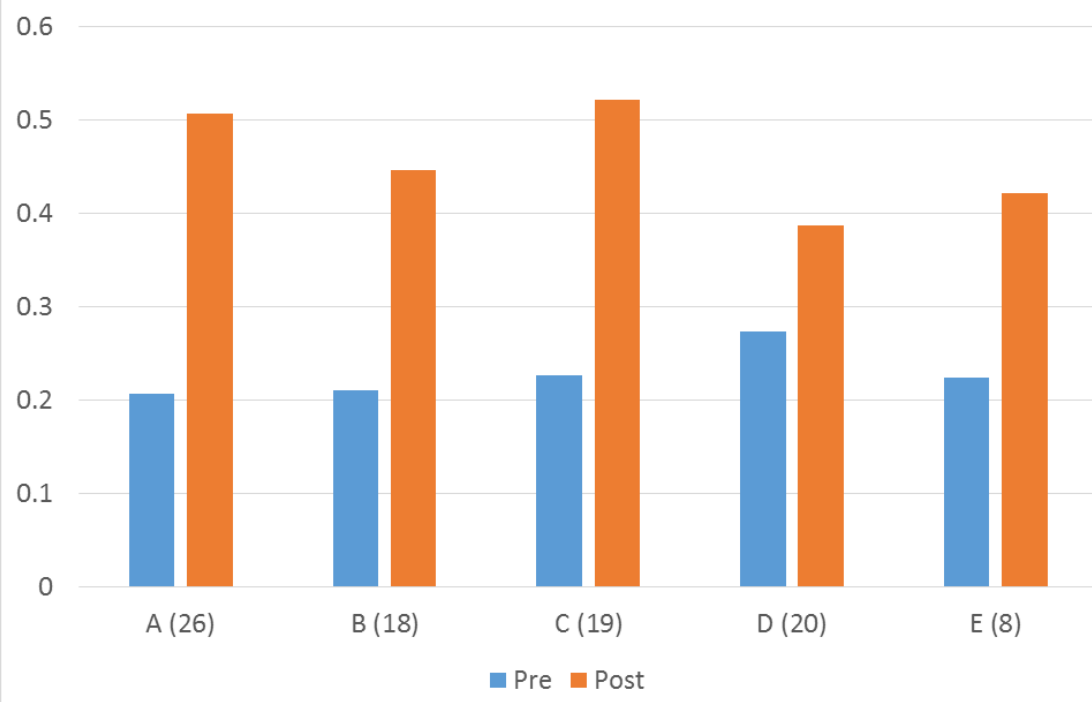

Figure 6. Students' concept inventory for the start (pre) and end (post) of the statics course The numbers in parentheses after the course label indicate the number of students in that section that took both the concept inventories.

The two way mixed ANOVA also showed there is also no statistically significant interaction in the larger sample between class section and score (pre- and post) on the concept inventory, $F(4$, $86)=2.31, p=.06$, partial $\eta^{2}=.10$. Similarly, the main effect of group (i.e., class section) showed that there was not a statistically significant difference in scores between classes $F(4,86)$ $=0.46, p=.77$, partial $\eta^{2}=.02$. There was, however, a significant main effect for time, showing that students in all sections made gains in knowledge over time. The main effect of time showed a statistically significant difference in Statics test scores at the different time points, $F(1,86)=$ 78.32, $p<.001$, partial $\eta^{2}=.48$. A closer examination of the changes over time revealed that the posttest score was .23 points higher than the pretest score.

An additional two-way mixed ANOVA test was run on Sections A \& C, which were taught by the same instructor, to provide the "strictest" test for whether student performance (pre, post, and retention) differed significantly between the control and the modified delivery method. Results from the analysis indicated that there was no statistically significant interaction between the type of class and score on the concept inventory over time, $F(2,52)=0.173, p=.796$, partial $\eta^{2}=$ .007. The main effect for the groups, collapsing across concept inventory scores was not statistically significant, $F(1,26)=0.33, p=.57$, partial $\eta^{2}=.012$. These results suggested there was no class (i.e., treatment) effect. As an additional indicator, exam performance between Sections A \& C were also compared.

\section{Exam Performance}

Due to scheduling rules at our university, it was not possible to hold a common final for the four 
fall sections. However, as Sections A and C where taught by the same instructor, it was possible to develop exam questions of similar difficulty for specific topics. Figure 7 shows the average student performance, separated by teaching methods, on a given exam question along with the standard deviation in the scores. Not only did section $\mathrm{C}$ typically perform slightly better, the standard deviations on the scores for section $\mathrm{C}$ also tended to be smaller than for Section $\mathrm{A}$. Section A only outperformed section $\mathrm{C}$ on two final exam questions where section A saw marked improvement over similar questions from a midterm as shown in Figure 7c. The small variations between exam scores reinforces the results of the ANOVA test.

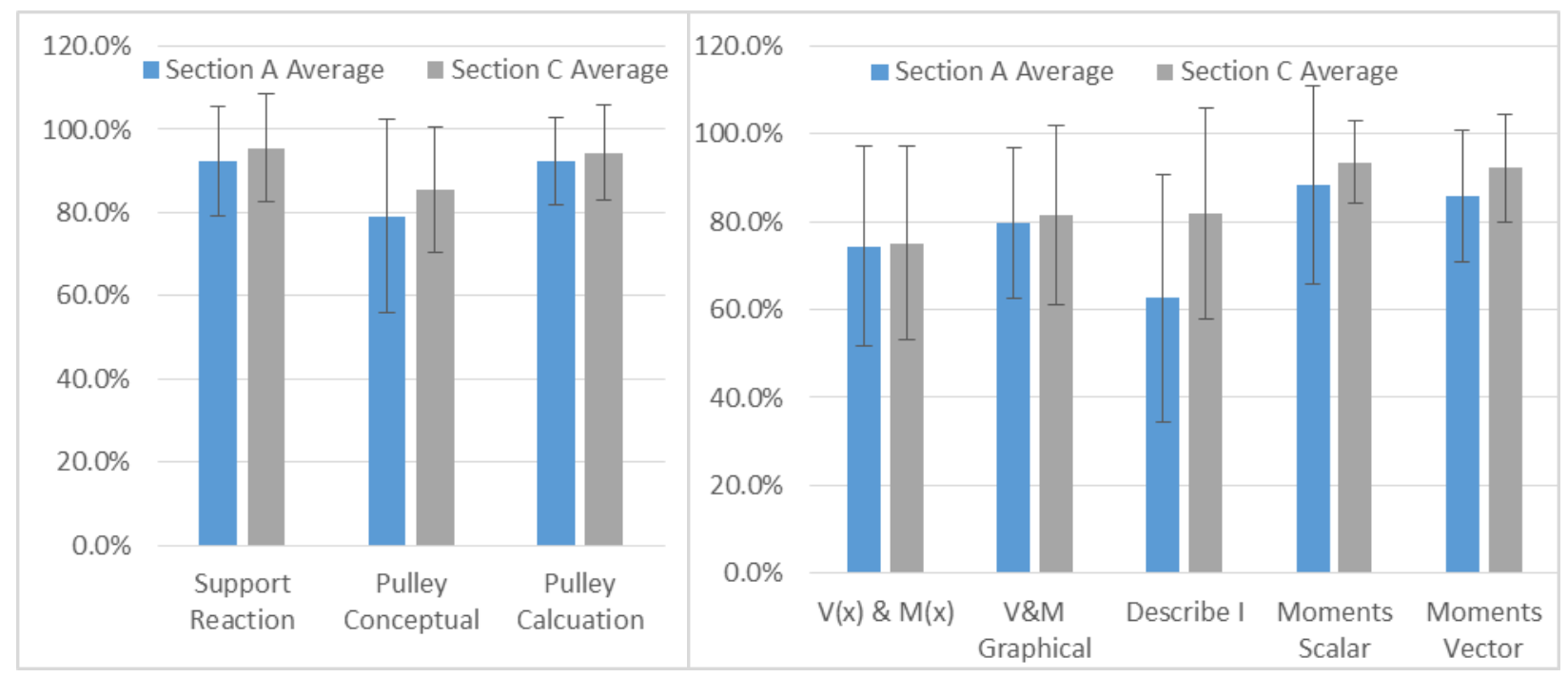

(a) Board Example vs. Hands-on Activity

(b) Flipped-flipped vs. Active Lecture

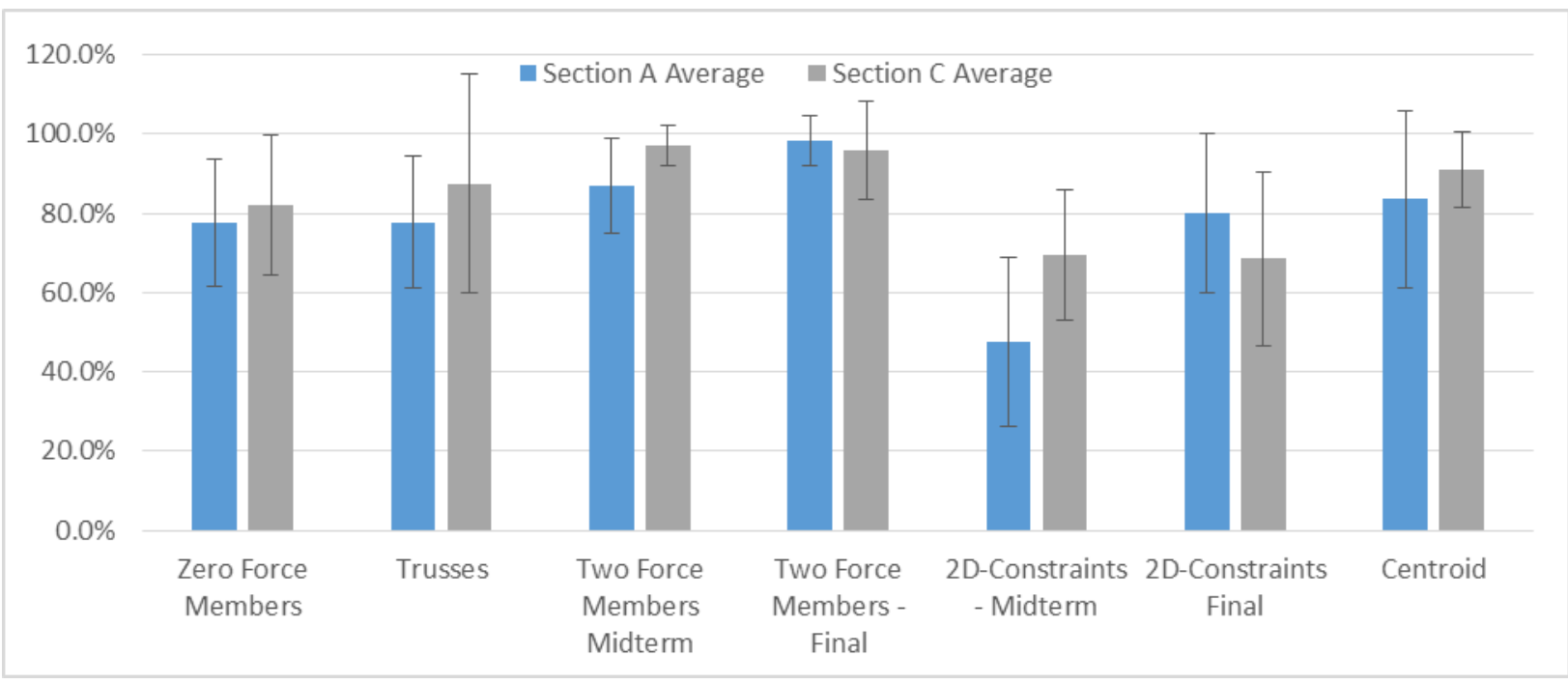

(c)Topics Taught by the Same Method

Figure 7. Sections $\mathrm{A}$ and $\mathrm{C}$ exam performance comparison. In section $\mathrm{C}$ all topics were taught using an active lecture. In section A, compared topics were taught using (a) hands-on activities, (b) the flipped-flipped model, or (c) the same active lecture as section $\mathrm{C}$. 


\section{Factors Affecting Student Performance}

A multiple regression analysis was completed to explore the effects of preexisting differences among the student groups, such as pre-requisite grade. The experience and training of the participating faculty in effectively implementing active learning techniques was also considered as a factor that could affect student performance as two of the professors were highly trained in the treatment technique and the other two professors were not. Thus, the four treatment classes were grouped into two categories: trained and untrained. While there is a confound of professor gender, with both female professors as the trained professors and the two male professors as the untrained professors, it was determined that this did not appear to have an effect on gender performance (male or female) in any of the sections. The control group was eliminated in this analysis as no significant difference was found in the student performance between the two classes taught by the same instructor.

The multiple regression was focused on just the pre- and post- concept inventory scores to retain a larger number of students and increase power and because, as previously discussed, there is no statically significant difference between the post- and retention average scores. The initial model included the following independent variables: student gender, class type (trained vs. untrained), pre-requisite grade, and pre-test score on the concept inventory. This model did not significantly

predict the variance in post-test Static scores, $F(4,65)=2.33, p=.07 . R^{2}$ for the overall model was 12.5 percent with an adjusted $R^{2}$ of 7.10 percent, a small size effect according to Cohen. ${ }^{11}$ When looking at which independent variables are statistically significant, only pre-requisite grade and class section were significant. The limited sample size, especially the number of female students, made it difficult to observe an effect.

After removing the gender and pre-test score, the multiple regression analysis showed class section and pre-requisite course grade statistically significantly predicted post- concept inventory scores, $F(2,81)=7.24, p<.001 . R^{2}$ for the overall model was 15.2 percent with an adjusted $R^{2}$ of 13.10 percent. The coefficient for pre-requisite grade is .089 . For each unit change in the prerequisite grade ( $\mathrm{C}$ to $\mathrm{C}+, \mathrm{B}$ - to $\mathrm{B}$ ), the model showed an expected post- score increase of .089 points, equivalent to 8.9 points higher on a 100 point scale. The coefficient for class section was 0.12 where students in the sections with faculty trained in delivery active-learning techniques scored 0.12 higher (or 12 points on a 100 point scale) than those students in the class sections taught by faculty less accustomed to the style of active teaching involved in the intervention.

\section{Results - Student Perceptions}

As a final homework assignment, students were asked to complete a survey regarding the course, the effectiveness of different course activities and the usefulness of the course videos. Students were asked to answer "Yes" or "No" if they felt the course activities increased their mastery of a topic, increased their interest in engineering, or did not contribute to their mastery of course content. Yes answers were assigned a value of 1.0 and No's were assigned a value of 0.0 . Averages over 0.5 would indicate a majority of students answered yes. Average answers for each section are shown in Figure 8.

More students in sections A, B, C and E indicated that course activities helped content mastery while more students in section $\mathrm{D}$ students did not think activities supported learning. Only section $\mathrm{C}$ had a majority of students indicating that course activities increased their interest in 
engineering. These results are interesting considering the majority of students in sections A, B, $\mathrm{C}$ and $\mathrm{E}$ indicated the course increased their interest in engineering with section D's interest unchanged as shown in Figure 9 and discussed below.

Questions directly related to the course required students to rank their interest in statics, perceived course difficulty, perceived class participation and the participation of their classmates, and perceived mastery of concepts. They rated these on a Likert scale with 1 indicating "Very Low", 3 indicating "Medium", and 5 indicating "Very High". Students also rated their interest in engineering as a result of taking the course with 1 indicating "Greatly Decreased", 3 indicating "Stayed the Same" and 5 indicating "Greatly Increased". Figure 8 summarizes these survey results by section.

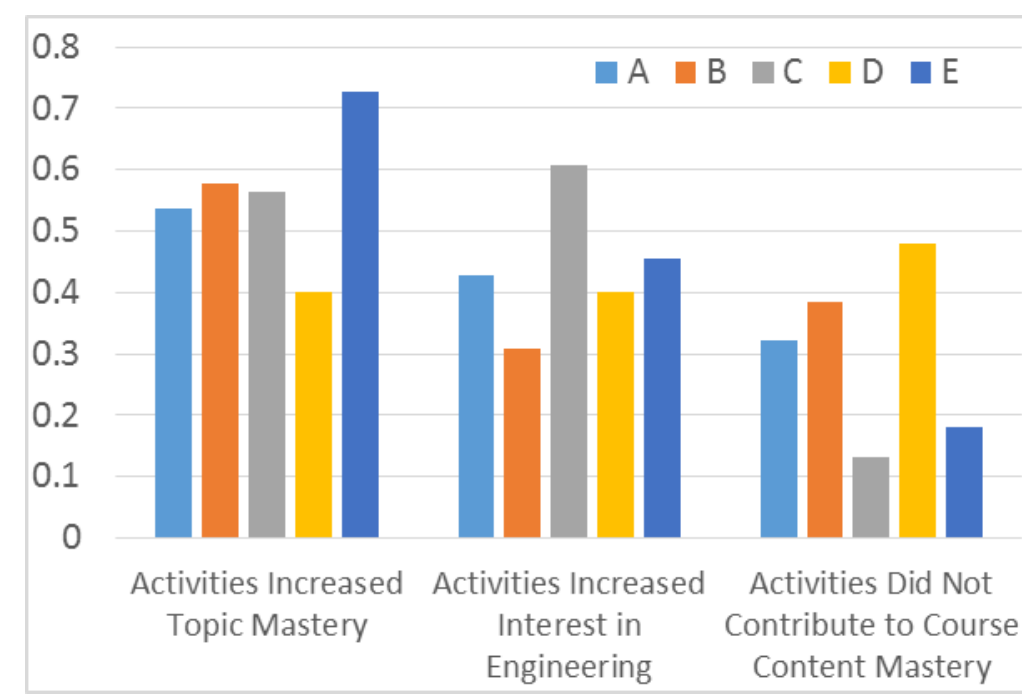

Figure 8. Average students survey responses for each section regarding the effectiveness of course activities. Yes $=1.0$ and $\mathrm{No}=0.0$.

The results presented in Figure 9 suggest a direct relationship between interest in statics and engineering and perceived level of difficulty. The sections with high higher rating for interest in the course and engineering have lower perceived levels of difficulties. Sections A and C saw the highest ratings for interest in statics and engineering with the lowest ratings for level of difficulty while Section D students rated interest in engineering lowest and suggested the course had a high level of difficulty. For the male students, section D found the course the most difficult and subsequently expressed the least interest in statics and engineering and reported the lowest selfparticipation. However, no section reported that their interest in engineering had decreased as a result of the course. It either "Stayed the Same" or "Increased".

The females of section B, who had the largest gain on the concept inventory (Table 4), gave the course the highest difficulty rating. While their interest in engineering "Stayed the Same", their interest in statics was higher than males or females in sections B and D. Female interest was higher in statics than males in the same section for all sections but section A where the females still reported an average higher than 3.5. Section $C$ unexpectedly reported the highest perception of self and class participation with average ratings over 4.0 for both males and females. No other section rated their involvement over 3.5. 


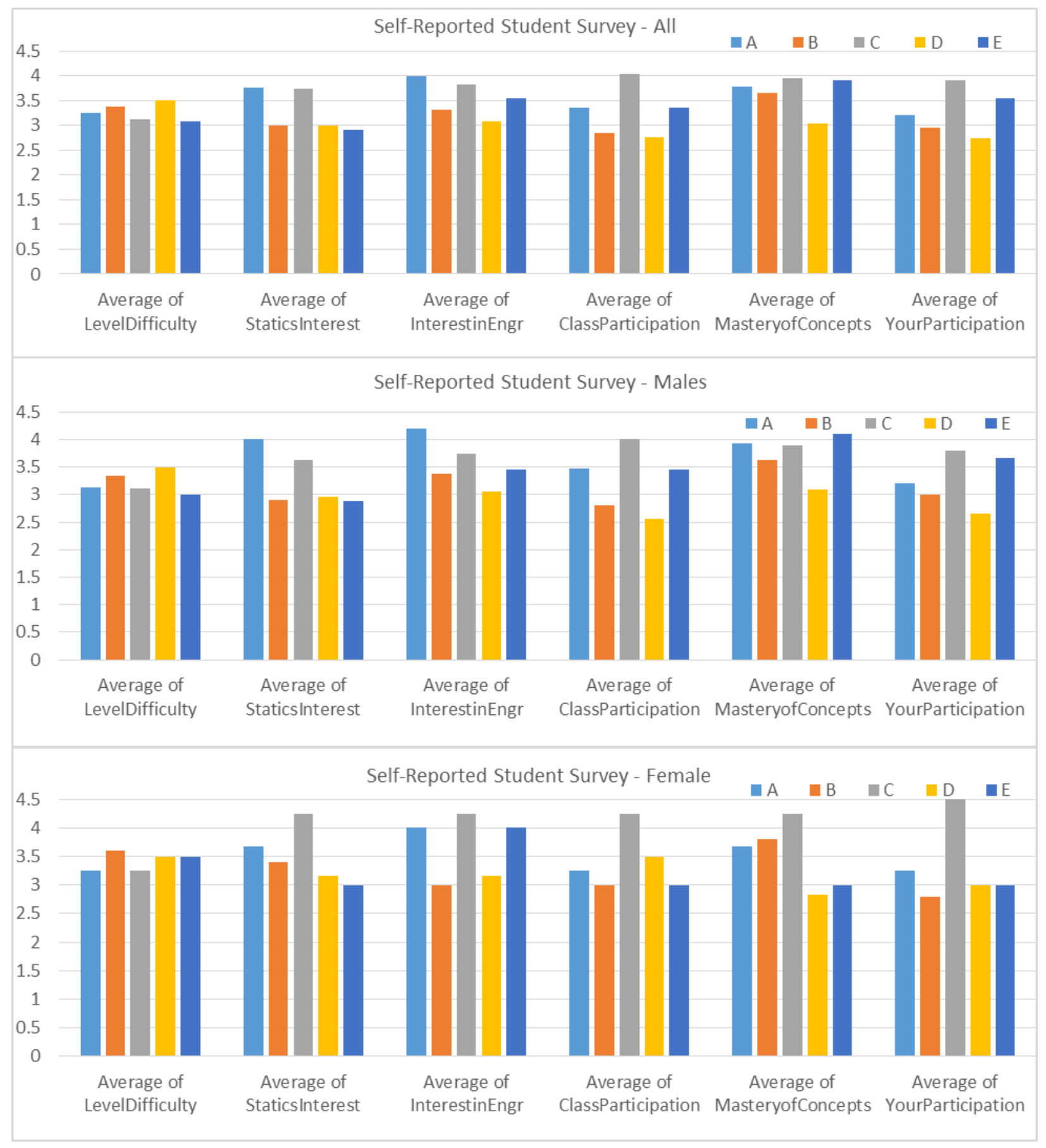

Figure 9. Student survey responses by gender and total for each section. Responses based on five point Likert scale with 1 indicating "Very Low" or "Greatly Decreased", 3 indicating "Medium" or "Stayed the Same" and 5 indicating "Very High" or "Greatly Increased."

\section{Discussion}

Student Performance and Perceptions:

The concept inventory results clearly indicate that sections A, C and E had the greatest pre- to post- knowledge gain, with section D's students showing the least improvement. These results 
appear to align with the students' self-reported perceptions of the course difficulty where sections $\mathrm{A}, \mathrm{C}$ and $\mathrm{E}$ found the class the least difficult and section D reported it the most. The students' perceptions of difficulty and performance also align with their self-reported interest in engineering and their view of their own class participation with section D reporting the lowest interest and participation and A, C and E the highest. Section B's results consistently were higher than section D's but less promising than A, C and E. Section A and section C, the control class that did not experience flipped, flipped-flipped or numerous hands-on activities but was still taught with active-learning approaches, both showed the greatest gains on the concept inventory and the strongest perceptions of class participation and interest in engineering with no statistical significance between the two sections' performance.

Why did sections B and D consistently underperform when compared to sections A, C and E? Why did the inclusion of flipped, flipped-flipped or numerous hands-on activities appear to make no difference in student learning and engagement? A number of external factors could have affected these results including: instructor training in active-learning pedagogies, class time, classroom facilities, and student preparation.

Professor 1, who taught sections A and C, uses a highly interactive teaching method refined over ten years of teaching. Professor 4, who taught section E, is a young faculty member who has embraced evidence-based teaching methods. Both Professors 1 and 4 are in positions with a primary focus on teaching. Professors 2 and 3, who taught sections B and D respectively, are both Full Professors with strong research backgrounds and little to no pedagogical training. While both are open to in-class questions, their teaching styles lean toward extensive lecture with models and demonstrations. Mid-quarter Professor 3 noted his students did not seem engaged during hands-on activities. It was determined he was not holding students responsible for completing the work by not asking students to report out intermediate and final answers or engaging with the students during the activities. An attempt was made mid-quarter to modify how activities were facilitated but student habits and attitudes were firmly established. Research by Freeman, et al. indicates that incorporating active practices in the STEM classrooms are the most important factors to increasing student engagement. ${ }^{2}$ Professors 2 and 3 did include activities in their courses but did not set the expectation for students to report out answers, allowing them to passively wait for the instructor to give the expected result. The higher postconcept inventory scores and self-reported interest and engagement of students in sections A, C and $\mathrm{E}$ are in-line with Freeman's work.

Section $\mathrm{E}$ is a special section for students who were behind in the physics sequence and not able to enroll during the fall quarter or for those students who either failed or withdrew from statics in the fall. Not surprisingly, the average incoming physics pre-requisite score for these students is noticeably lower than the other sections as shown in Table 3. The regression analysis indicated these students should have the least gain on the concept inventory, losing 0.089 points out of 1.0 for each incremental decrease in pre-requisite grade. However, the students in Section E, as a class, saw greater percent gains on the concept inventory than either Section B or D. The 0.089 points loss appears to be offset by the 0.12 points gain seen in students of an instructor with training in active-learning pedagogies. 
Student intrinsic motivation and self-efficacy is known to improve student engagement and performance. ${ }^{12}$ Professors 1 and 4 began their quarters with discussions on best practices for student success, explained why the course was using active learning techniques, and learned student names by the second week. Professors 2 and 3 report not learning names or explaining the purpose of the active learning modules. Professor 3 did tell the students he was using material developed by other faculty without providing a full explanation of the effort. As learned through private communications with students and student evaluation comments, the section D students assumed Professor 3 was not preparing for class and simply using another instructor's notes. This, combined with the lack of interaction and facilitation of the hands-on activities, resulted in very low motivation and performance in the section D students and significantly reduced teaching ratings for Professor 3 per his normal evaluations

An instructor's teaching methods also appears to have a greater effect on student perception of engagement than actually completing hands-on activities. Section $\mathrm{C}$, the section with the least number of hands-on and group activities, reported the highest participation numbers. Professor 1 's regular teaching style includes regularly calling on students by name to help solve board examples and answer conceptual questions. Lectures are also regularly broken up with group and individual work ranging from two minute to fifteen minute activities. This "active-lecture" was used for all of section C's lessons and in section A when a lesson's curriculum was not altered. For the twelve modified lessons, students in section A completed a significantly larger amount of group and individual work, including hands-on physical activities that could take the entire class period, with the students regularly required to report out results. It appears the students of Sections A, B, D and E did not perceive these group activities as class participation.

Section D appears to have been disadvantaged both in class time and location. Sections A, B and $\mathrm{C}$ were taught on MWF, back-to-back, in the same pilot classroom that has whiteboard paint on all four walls, desks on rollers and seven projector screens that project directly onto the writeable walls easily allowing student groups to report answers on projected problems. Each section was 65 minutes long with section A starting first at 9:15 am. Section E was also taught MWF in the same pilot classroom during the winter quarter. The $\mathrm{T} / \mathrm{Th}$ section $\mathrm{D}$ had the earliest start time at 8:30 am and required students to engage for 100 minutes. The class was taught in a traditional classroom where the projector screen covered close to half of the room's two chalkboards. The desks were not on wheels and were tightly packed in linear rows that made walking to a student's desk uncomfortable for both the instructor and the students. Section D was disadvantaged by its early start time and longer class sessions. While most faculty can anecdotally show that students, especially college sophomores, struggle with early classes and perform better in afternoon sections, Folkard, et al has shown this to be true in school children. ${ }^{13}$

Section D's schedule also negatively affected the instructor's ability require regular material review and distributed practice to the same extent as sections $\mathrm{A}, \mathrm{B}, \mathrm{C} \& \mathrm{E}$. In all five sections, homework was due at every class meeting to ensure students stayed current in the course and resulted in an average of three homework problems due each lesson for the MWF sections (sections A, B, C \& E). To limit student work overload in the T/Th section, Professor 3 would typically require approximately one-third of the week's homework be turned in on Thursday and the remaining two-thirds the following Tuesday. This meant that not all the material covered on Tuesday required review to complete the homework due at the start of Thursday's class. 
Distributed practice and material review within one to two days have both been found as key components to long-term student learning. ${ }^{14,15}$

\section{Knowledge Retention}

The retention data analyzed for the 51 students who took all three iterations of the concept inventory are encouraging. For material that is only learned superficially, one would expect students to retain approximately $20 \%$ after four weeks. ${ }^{16}$ However, with repeated exposure, especially review within the first 24 hours, the amount of material lost will be reduced. Deeper learning is also formed if students are able to relate the material to something they have learned experientially or are familiar with in their everyday lives. ${ }^{17}$ As the retention concept inventory scores increased for all sections, it appears the students from all sections retained the material learned in the statics course. This suggests including best-practices of active-learning, distributed practice and experiential learning supported students regardless of individual instructor's expertise in pedagogy.

\section{Gender Differences}

Regardless of section or professor, female students showed the lowest pre-test scores but the greatest learning gains on the concept inventory, with actual post- scores higher for females than males in sections B, D and E. Table 5 compares the average grade for the prerequisite physics course to the grade earned in statics. While actual grades cannot be compared due to difference in instructors, grading schemes, etc., it is important to note that female students in sections A and $\mathrm{E}$ had lower prerequisite grades but outperformed male students. Female students in section $\mathrm{C}$ experienced a greater improvement in course grades than their male counterparts. In section $\mathrm{D}$, where the collaboration and group work was not as strongly encouraged, the male and female students maintained a similar difference in their average grades.

Table 5. Student grades in Statics and prerequisite Physics by gender for all sections.

\begin{tabular}{|c|c|c|c|c|}
\hline & \multicolumn{2}{|c|}{ Average Physics Grade with CR } & \multicolumn{2}{c|}{ Average Statics Course Grade } \\
\hline Section & Female & Male & Female & Male \\
\hline A & 2.65 & 3.12 & 3.13 & 2.94 \\
\hline B & 3.34 & 3.06 & 3.33 & 2.93 \\
\hline C & 2.64 & 3.16 & 3.07 & 3.46 \\
\hline E & 2.80 & 2.93 & 3.10 & 3.29 \\
\hline
\end{tabular}

Research shows that active learning methods that include collaboration and non-competitive group work have a greater impact on female students in terms of performance and engagement. ${ }^{18,}$ ${ }^{19}$ This work highlights that simply including hands-on activities and group work, even if the professor does not teach interactively, still has a strong effect on females and allowed the female students to catch up to their male colleagues. Interestingly, the section $\mathrm{C}$ females scored the lowest among females on the post-concept inventory suggesting female students may receive more benefit from hands-on activities than just demos and from flipped methods of teaching.

\section{Conclusions}

The promising results on student material retention and female engagement and performance illustrates the need to continue this work to fully answer the research questions. It also leads to a 
new question for future work regarding which active methods are the most effective for underrepresented students including females.

The following summarizes what was learned about the current research questions:

1. Does inverting the statics classroom help to improve student self-reported participation?

Within this limited data set, student self-perceptions of class participation did not indicate that inverting the classroom was more effective in engaging students than an active lecture. Instead, the results indicate that having an instructor trained on active methods is more indicative of participation and interest in engineering. This work also reinforces the work of Freeman, et.al. showing that more active sections generally reported greater interest in engineering and statics, performed better on the post- concept inventory and retained more information on concept inventories given 1 month or 4 months later.

2. How do flipped-flipped approaches compare to the standard flipped model in terms of student perception of teaching effectiveness and their reported engagement?

The flipped-flipped model was considered more useful by a majority of students, regardless of class section, to a regular flipped approach. However, as seen in the comparison of exam questions for sections $\mathrm{A}$ and $\mathrm{C}$, the topics covered using the flipped-flipped approach did not lead to a greater gain in mastery of topics. To better answer this question in the future, topics that are covered on the concept inventory should be taught using the flipped-flipped approach and compared to concept inventory gains of topics taught using the flipped approach.

3. Is a demo enough? Should students do a hands-on activity for deeper learning and engagement?

The limited data set available shows that a demo might be enough, as long as it is presented in an active classroom that challenges students to engage. Students in the control section who observed demonstrations of behaviors instead of experiencing the behavior in a structured hands-on activity performed equally or better than the students who completed the activities. This suggests that the demo is only enough if it is presented in an active classroom and hands-on activities still need faculty interaction with students to reach deeper learning and engagement.

4. Does inverting the statics classroom increase material knowledge gain?

All students showed retention of course material regardless of instructor or delivery method, however, the statistically significant difference between students in section A and E (with trained instructors) versus section $\mathrm{C}$ and $\mathrm{D}$ (with untrained instructors) suggest that a highly interactive classroom does increase material gain from beginning to end of the course.

There were a number of lessons learned that other researchers can apply to build upon this work or to simply increase student engagement in their own courses. The authors hope to use these 
lessons to repeat this work during the fall 2016 quarter to expand the data set and further answer the research questions. These lessons include:

- Work with university administrators to hold a common final. This would allow a more accurate assessment of student learning in the flipped-flipped modules and other topics that are not assessed by the concept inventory.

- Choose topics to modify with care. It is natural to pick topics that students historically struggle with in an effort to improve student learning but it is important to establish useful means to assess the effectiveness of the modifications.

- Ensure greater controls for methods used in the control group versus the pilot course.

- Generate student buy-in from the start to help build student intrinsic motivation and engagement, which improves student learning.

- Check in often with students during activities both individually and as a class to keep students engaged and ensure students are reaching the desired activity outcomes.

- Collaborative group work has a disproportionally strong influence on female student performance and engagement. STEM courses should include these types of activities regularly.

- Active teaching methods and homework due at each class meeting promote student behaviors that are strongly associated with durable learning.

The study on pedagogical changes to a statics classroom at Santa Clara University highlighted the large number of factors that contribute to student success or struggle in mastery of fundamental engineering concepts. There are many factors that engineering faculty cannot control, including the time and classroom where a class is taught, the time of final exams, the time students do their work, just to name a few. There are, however, some factors that can be controlled by faculty that this study highlights are predictors of student success. The first is the incoming prerequisite course. The data collected shows a statistically significant relationship between incoming physics grade and average score on the post- course concept inventory, thus reiterating the need to enforce prerequisite requirements. The second factor that can be controlled by the faculty is the faculty's training in active learning methods. Increasing training on active classroom methods can increase student engagement and learning gains and should be a priority for engineering departments.

\section{Acknowledgements}

The authors would like to thank the Santa Clara University Office of Faculty Development for the support of the Teaching with Technology grant to develop the course modules and hands-on activities applied in this work, the Santa Clara Assessment Office for their assistance with statistical analysis, and our two colleagues for their willingness to experiment and use the developed teaching modules. 


\section{Bibliography}

1. Higher Education Research Institute (nd). HERI Faculty Survey. Retrieved January 5, 2016 from http://www.heri.ucla.edu/facoverview.php

2. Freeman, S., Eddy, S., McDonough, M., Smith, M., Okoroafor, N., Jordt, H., \& Wenderoth, M. P. “Active learning increases student performance in science, engineering, and mathematics.",Proceedings of the National Academy of Sciences, 11(23), pp. 8410-8415, 2014 Retrieved October 27, 2015 at: http://www.pnas.org/content/111/23/8410.full.pdf

3. Dollar, A. and P. Steif. "A Web-based Statics Course using and Inverted Classroom". Proceedings of the ASEE Annual Conference \&Exposition, Austin, TX, June 2009.

4. Papadopoulos, C., Santiago-Román, A., \& Portela, G. (2010, October). Work in Progress-Developing and Implementing an Inverted Classroom for Engineering Statics. In Proceedings-40th Annual Frontiers in Education Conference.

5. Bland, L. (2006), Apply Flip/Inverted Classroom Model in Electrical Engineering to Establish Life-long Learning, in Proceedings of the ASEE Annual Conference 2006. Chicago, IL.

6. Kellogg, S. (2009) Developing Online Materials to Facilitate and Inverted Classroom Approach, ASEE/IEEE Frontiers in Education Conference, Session T3F, San Antonio, TX

7. Rais-Rohani, M., Walters, A., and Vizzini, A. (2010), Emporium Based Redesign of Statics: An Innovative Approach to Enhance Learning and Reduce Costs. ASEE Annual Conference and Exposition. 2010. Louisville, KY.

8. Plotnikoff, D. (2013), "Classes should do hands-on exercises before reading and video, Stanford researchers say", Stanford Daily News, July, 16, 2013 - On-line: http://news.stanford.edu/news/2013/july/flipped-learningmodel-071613.html (Referenced: May 28, 2015)

9. Estes, A., Welch, R., \& Ressler, S. "The ExCEEd teaching model", Journal of Professional Issues in Engineering Education and Practice, pp. 218-222, October 2005

10. Steif, P. S., \& Dantzler, J. A., "A statics concept inventory: Development and psychometric analysis. Journal of Engineering Education”, 94(4), pp. 363-371, 2005

11. Cohen, J. (1988). Statistical power analysis for the behavioral sciences (2nd ed.). Hillsdale, NJ: Lawrence Earlbaum Associates, 1988

12. Herman, G., "Designing contributing student pedagogies to promote students' intrinsic motivation to learn", Computer Science Education, Vol. 2, No. 4, pp. 369-388, 2012

13. Folkard, S., Monk, T., Bradbury, R., \& Rosenthall, J., "Time of day effects in school-children's immediate and delayed recall of meaningful material", British Journal of Psychology, Vol. 68, 1, pp. 45-50, 1977

14. Oxford, R., Teaching \& Researching: Language Learning Strategies, Routledge, New York, NY, 2013

15. Ausubel, D.P., The Acquisition and Retention of Knowledge, Springer Science+Business Media, 2000

16. Ebbinghaus, "Memory: A Contribution to Experimental Psychology -- Ebbinghaus (1885/1913)". Retrieved 2016-01-29 from http://psychclassics.yorku.ca/Ebbinghaus/index.htm).

17. Nilsson, T, "Why Am I Learning This? Using Everyday Examples in Engineering to Engage Female (And Male) Students in the Classroom", American Society of Engineering Education Conference, Indianapolis, IN, June 2014

18. J. Gaffney, E. Richards, M.B. Kustusch, L. Ding, and R. Beichner, "Scaling up education reform",Journal of College Science Teaching, 37 (5), 2008

19. Weston, T., Seymour, E., \& Thiry, H., Evaluation of Science Education for New Civic Engagements and Responsibilities (SENCER) Project, Prepared for the National Center for Science and Civic Engagement, Dec. 2006. Retrieved on 2016-01-24 from http://www.sencer.net/assessment/pdfs/final report sencer $122106 . p d f$, 